\title{
AVALIAÇÃO ESPAÇO-TEMPORAL DA RELAÇÃO ENTRE O ESTADO TRÓFICO DO RESERVATÓRIO DE BARRA BONITA (SP) E O POTENCIAL POLUIDOR DE SUA BACIA HIDROGRÁFICA
}

\author{
Assessment of the space-time relationships between the UHE Barra Bonita \\ Trophic State and its drainage basin pollution potential
}

\author{
Rachel Bardy Prado \\ Pesquisadora Embrapa Solos (CNPS) \\ rachel@cnps.embrapa.br
}

Evlyn Márcia Leão de Moraes Novo

Pesquisadora Instituto Nacional de Pesquisas Espaciais (INPE)

evlyn@ltid.inpe.br

Artigo recebido para publicação em 22/02/2007 e aceito para publicação em 07/08/2007

RESUMO: $\quad$ Esta pesquisa foi proposta devido ao processo de acelerada degradação da qualidade da água em regiões bastante populosas, o qual resulta, em grande parte, do uso e ocupação da terra inadequados. Assim sendo, este objetiva avaliar a relação entre o estado trófico do reservatório de Barra Bonita (SP) e o potencial poluidor da bacia hidrográfica de contribuição no espaço e no tempo. A determinação do estado trófico do reservatório de Barra Bonita baseou-se em amostras coletados em 30 estações distribuídas homogeneamente na superfície do lago em duas datas: 1990 e 2002. Com base nessas amostras foram determinados os parâmetros necessários à aplicação do Índice de Estado Trófico (IET), cujos resultados foram espacializados utilizando-se o ArcView 3.2 da ESRI. Para determinar o potencial poluidor da bacia foram obtidas imagens do satélite Landsat referentes também à 1990 e 2002. Essas imagens foram submetidas a classificação (dizer o tipo) de modo a se obter mapas de uso e cobertura da terra. Foram também obtidos dados sobre o crescimento populacional da bacia e dados para o cálculo da carga de nitrogênio e fósforo lançada pela população, via esgoto sanitário, nos corpos hídricos da bacia. Os resultados mostraram que ocorreu um incremento significativo do nível trófico da água, entre 1990 e 2002 de forma diferenciada para cada compartimento do reservatório em questão. A degradação da qualidade da água, expressa pelo nível trófico foi muito mais intensa no braço do rio Tietê, cujos pontos apresentaram como eutróficos tanto em 1990 como para 2002 devido à contribuição de fontes de poluição da cidade de São Paulo. A avaliação integrada dos sistemas aquático e terrestre, no espaço e no tempo, permitiu concluir que a degradação da qualidade da água possui forte relação com as alterações no uso e cobertura da terra e com o aumento populacional, traduzidos em fontes difusas e pontuais de poluição e que estas alterações podem ser detectadas aplicando-se geotecnologias. Outro aspecto relevante dos resultados foi o de verificar que o potencial poluidor da bacia hidrográfica não é espacialmente homogêneo, e que portanto, as medidas de controle de poluição precisam ser focadas nas áreas mais críticas, onde a degradação é mais intensa. 
Palavras-chave: Barra Bonita, qualidade da água, uso das terras, poluição pontual e difusa.

ABSTRACT: This research aimed to understand the fast water degradation process in overpopulated áreas as a result of inadequate land use and land cover practices. Therefore, the objetive of this study is to assess the relationship between the trophic state of the Barra Bonita Reservoir(SP) and the pollution potential of its drainage basin in space and time. The trophic state determination was based in water samples collected at 32 stations evenly distributed in the lake in two dates: 1990 and 2002. These samples were used to determine the key parameters for the computation of the Trophic State Index (TSI), which was then spatialised with aid of the ESRI ArcView 3.2 sofware. The pollution potential was based on several data: land use and land cover maps derived from the Landsat /Thematic Mapper images acquired in 1990 and 2002; population growth and nitrogen and phosphor load. The results showed the increase in the water trophic level from 1990 to 2002, but this increase was not homogenous. The water quality degradation, as expressed by the TSI was highest in Tietê river compartment due to response to the higher pollution potential of São Paulo city. The space and time integrated analyses of the terrestrial and aquatic system allowed to conclude that the water quality degradation is closely connected to both land use and land cover changes in the drainage basin and to the population growth. Other important finding was that the pollution potential is not homogenous throughout the drainage basin, and that therefore, the pollution control police must be focused in more critical areas, where the degradation is more intense.

Keywords: Barra Bonita, water quality, land use/land cover, point and nonpoint pollution.

\section{INTRODUÇÃO}

Diversos são os fatores que levam à deterioração da água, podendo ser suas fontes classificadas em pontuais e difusas. As fontes pontuais correspondem, essencialmente, aos efluentes domésticos e industriais, já as difusas incluem os resíduos provindos principalmente da agricultura (fertilizantes, herbicidas, inseticidas, fungicidas, entre outros). Este tipo de poluição pode ser intensificado devido à irrigação, à compactação do solo derivada da mecanização, ao desflorestamento (inclusive de mata ciliar), à ausência de práticas conservacionistas do solo, aos processos erosivos, além da interferência de fatores naturais (geologia, geomorfologia, declividade, pedologia, forma e densidade de drenagem da bacia hidrográfica, regime de chuvas, permeabilidade do solo e outros). A situação parece grave visto que existem estimativas (Loague et al., 1998) de que, aproximadamente, de 30 a $50 \%$ dos solos da
Terra estejam afetados por poluentes provindos de fontes difusas os quais atingem os cursos d'água gradativamente.

No tocante aos reservatórios, ocorrem impactos negativos consideráveis no sistema aquático desde a fase de sua construção. Esses impactos se refletem na qualidade da água visto que a presença do reservatório provoca a redução da capacidade de autodepuração do curso d'água, o aumento da retenção de sedimentos e nutrientes e a alteração das características físicas, químicas e biológicas do sistema. Desta forma, ocorre um incremento no processo de eutrofização o qual, dependendo do nível atingido, poderá comprometer os usos múltiplos a que esse é destinado.

No caso do reservatório de Barra Bonita, vários estudos vêm sendo realizados nas últimas décadas, o que tem contribuído para uma melhor 
avaliação de seu estado trófico. Matsumura-Tundisi, 1990; Calheiros, 1993; Novo e Braga, 1995; Wisniewski, 1998; Calijuri, 1999, entre outros, obtiveram resultados que demonstraram a eutrofização intensa do reservatório.

Este processo tem ocorrido porque Barra Bonita é um reservatório antigo, localizado numa região sujeita a intensas transformações nos padrões de uso e ocupação da terra, o que o torna suscetível a problemas de poluição e assoreamento acelerado. Um fator agravante é a contaminação da água por substâncias químicas, provindas principalmente, de resíduos industriais e agrícolas. O aporte de nutrientes no reservatório é causado, em grande parte, pela entrada dos seus principais afluentes, o rio Tietê e o rio Piracicaba, os quais transportam, além dos resíduos agrícolas, descargas domésticas e industriais de grandes centros urbanos.

Existem numerosos estudos que demonstram haver uma alta correlação entre a distribuição espacial das atividades humanas, o estado de conservação da cobertura vegetal na bacia hidrográfica e o nível de degradação dos recursos hídricos (Thorton, 1990; Kira e Sazanami, 1995; Tufford et al., 1998). Existe, portanto, uma preocupação mundial em buscar identificar as causas desta degradação, considerando a relação do homem com os recursos naturais. Neste contexto, pode ser citada ainda uma iniciativa internacional do Programa Ambiental das Nações Unidas/ United Nations Environmental Program (UNEP) por meio do projeto denominado The Global International Waters Assessment (GIWA) visando conduzir uma avaliação dos problemas ambientais e seus impactos no ambiente. Esta avaliação está sendo realizada levando em consideração o valor intrínseco dos sistemas aquáticos, enquanto a avaliação dos impactos sócio-econômicos está focada no uso humano do ambiente (Daler et al., 2001).

Porém, no Brasil e, principalmente em Barra Bonita, são poucos os estudos que visem avaliar o relacionamento entre o uso da terra e as propriedades da água levando em conta as características da bacia de drenagem. Dentre as pesquisas realizadas, pode- se desta cara a contribuição de Refosco (1994), Piao (1995) e Pereira-Filho (2000).

Neste sentido, o presente trabalho foi realizado buscando verificar as relações entre as mudanças de estado trófico do reservatório de Barra Bonita, entre 1990 e 2002, e as transformações no espaço e no tempo dos fatores antrópicos da bacia hidrográfica os quais podem ser considerados controladores das variações da qualidade da água.

\section{2. ÁREA DE ESTUDO}

O reservatório de Barra Bonita começou a operar em 1963, sendo formado pelo represamento dos rios Tietê e Piracicaba, contando com a participação de vários afluentes. Este reservatório foi construído, principalmente, para a geração de energia elétrica. Porém, atualmente, é também utilizado para transporte fluvial (Hidrovia Tietê-Paraná), irrigação, turismo, lazer, pesca, abastecimento urbano e como suporte ao desenvolvimento do complexo industrial da região. A bacia hidrográfica de contribuição para o reservatório de Barra Bonita, adotada neste trabalho, é constituída por parte das bacias hidrográficas Piracicaba/Capivari/Jundiaí (BHPCJ) e Tietê/Sorocaba (BHTS), correspondendo a aproximadamente 19.164,43 km². Encontra-se inserida entre as coordenadas geográficas $21^{\circ} 54^{\prime} 20^{\prime \prime}$

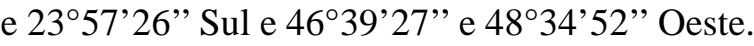

A Figura 1 mostra a localização da bacia no Estado de São Paulo e no Brasil, estando em UTM fuso 23 estendido, porque foi a projeção adotada no presente trabalho.

Trata-se de uma das regiões mais populosas e desenvolvidas do interior do Estado de São Paulo, concentrando cerca de $16 \%$ de sua população. Os problemas referentes à qualidade da água advindos do uso e cobertura da terra são bastante representativos da realidade de toda a extensão da BHPCJ e BHTS. 


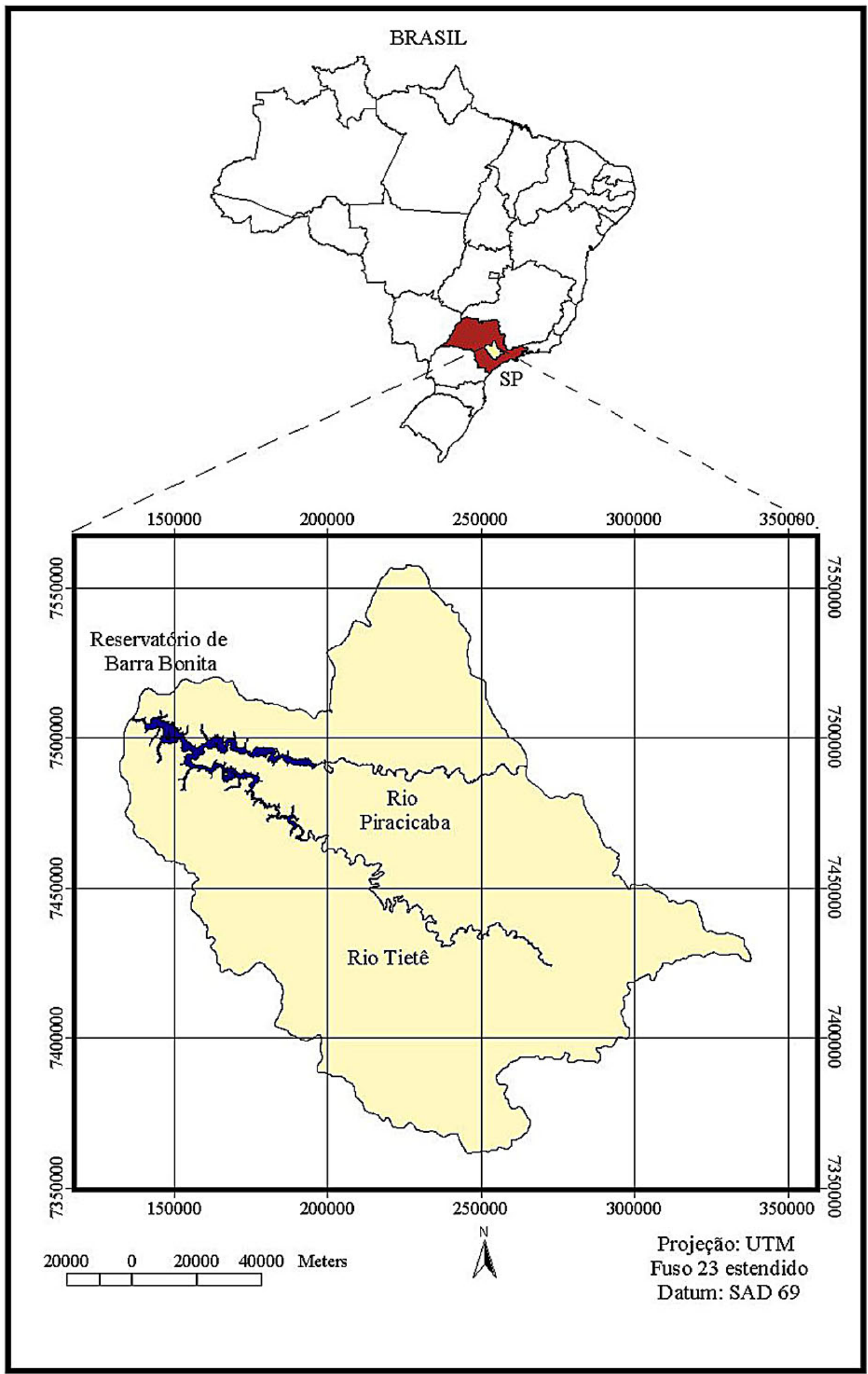

Figura 1. Localização da bacia hidrográfica de estudo no Estado de São Paulo e Brasil.

Sociedade \& Natureza, Uberlândia, 19 (2): 5-18, dez. 2007 


\section{MATERIAL E MÉTODOS}

\section{1. Índice de estado trófico do reservatório para 1990 e 2002}

Para estimar o estado de trofia do reservatório de Barra Bonita, utilizou-se o Índice de Estado Trófico (IET) de Carlson (1974), modificado por Toledo et al. (1983), considerando os dados obtidos na superfície da água do reservatório em 1990 e 2002, referentes a 30 pontos amostrados durante a estação chuvosa. Os dados de qualidade da água referentes a 1990 foram obtidos a partir do projeto Sensoriamento Remoto de Sistemas Aquáticos (SISA) (Novo e Braga, 1991 e 1995). Já os dados de 2002 foram obtidos por Prado (2004), sendo os pontos de coleta e métodos analíticos utilizados (APHA, 1995) mantidos constantes para que fossem passíveis de comparação. Para facilitar a análise multitemporal dos dados limnológicos, os 30 pontos amostrados foram agrupados por compartimento do reservatório de Barra Bonita: "braço" do rio Piracicaba - P (pontos de 1 a 11), "braço" do rio Tietê- $\mathrm{T}$ (pontos de 14 a 24), "corpo" central - C (pontos de 25 a 29) encontro dos "braços" - E (pontos 12 e 13) e barragem - B (ponto 30), como mostra a Figura 2. O IET considera os valores obtidos para transparência da água (S) em m, fósforo total (P) em mg/ $\mathrm{L}$, fosfato inorgânico $\left(\mathrm{PO}_{4}\right)$ em mg/L e clorofila (CL) em $\mathrm{mg} / \mathrm{L}$, cujas expressões são dadas, respectivamente, pelas equações:

$$
\begin{gathered}
\operatorname{IET}(\mathrm{S})=10 \times\{6-[(0,64+\operatorname{lnS}) / \ln 2]\}(1) \\
\operatorname{IET}(\mathrm{P})=10 \times\{6-[\ln (80,32 / \mathrm{P}) / \ln 2]\}(2) \\
\operatorname{IET}\left(\mathrm{PO}_{4}\right)=10 \times\left\{6-\left[\ln \left(21,67 / \mathrm{PO}_{4}\right) / \ln 2\right]\right\}
\end{gathered}
$$

$\operatorname{IET}(C L)=10 \times\{6-[(2,04-0,695 \operatorname{lnCL}) / \ln 2]\}$



Figura 2. Localização dos pontos de amostragens de água em 1990 e 2002 no reservatório de Barra Bonita - SP sobre a imagem ETM+ Landsat 7 de 2002 e limites municipais do entorno. 
De acordo com Toledo et al. (1983), a profundidade do disco de Secchi é muito afetada pela elevada turbidez dos reservatórios na maior parte do ano. Assim, para controlar tal problema, estes autores sugerem ponderar o IET médio, de forma a dar menor peso à variável transparência da água, da seguinte forma:

$\operatorname{IET}($ médio $)=\operatorname{IET}(\mathrm{S})+2\left[\operatorname{IET}(\mathrm{P})+\operatorname{IET}\left(\mathrm{PO}_{4}\right)+\operatorname{IET}(\mathrm{CL})\right] / 7$ (5)

A partir do IET médio obtido pela equação

5, o critério de classificação adotado foi:

Oligotrófico se: IET $\leq 44$

Mesotrófico se: $44<$ IET $<54$

Eutrófico se: IET $\geq 54$

\subsection{Potencial poluidor difuso da bacia em função da dinâmica do uso e cobertura da Terra}

Primeiramente, foram obtidos os mapas de uso e cobertura da terra de 1990 e 2002 da bacia hidrográfica em questão, em escala aproximada de 1:50.000. Para tal, foram processadas, segmentadas e classificadas imagens TM e ETM+ dos satélites Landsat 5 e 7, para 1990 e 2002, respectivamente. Os softwares utilizados nesta fase foram Envi 3.4 RT e Spring 3.6. As classes obtidas a partir do processamento foram posteriormente ponderadas. Para se atribuir os pesos às classes contou-se com a experiência profissional de técnicos especialistas no assunto, bem como o conhecimento prévio da área de estudo. Os critérios de ponderação encontram-se amplamente descritos em Prado (2004).

Adotou-se o pressuposto de que quanto mais tempo o solo permanecer exposto, maior o seu potencial para processos erosivos e, portanto, para o transporte de poluentes aos cursos d'água. Por outro lado, quanto maior a densidade da cobertura vegetal, menor o potencial erosivo. Modelos empíricos preditivos têm sido desenvolvidos considerando fatores relacionados às perdas de solo como características do solo, declividade, cobertura vegetal, entre outros aspectos (Ranieri, 1996; Donzeli et al., 1994; Pinto, 1996, dentre outros).
Desta forma, as classes obtidas para os mapas de uso e cobertura da terra 1990 e 2002 foram organizadas em cinco níveis de contribuição quanto ao potencial poluidor que afeta o reservatório de Barra Bonita, conforme mostra a Tabela 1.

\subsubsection{Obtenção do crescimento populacional e da carga de nitrogênio e fósforo lançada na bacia hidrográfica em estudo via esgoto sanitário}

O crescimento populacional é uma das principais causas da degradação da qualidade da água, visto que proporcionalmente a ele, há um aumento também da produção de resíduos líquidos, que na sua maioria são lançados in natura nos corpos d'água. A partir do levantamento do número de habitantes de 1990 e 2002 nos municípios com mais de 70\% de sua área na bacia estudada (SEADE, 2004), foi possível determinar o crescimento da população neste período.

O cálculo da carga anual destes elementos lançada por uma determinada população baseou-se em estudos de Arceivala (1981), segundo o qual cada habitante elimina, em média, por meio do esgoto sanitário 0,002 kg de fósforo (P) e 0,008 kg de nitrogênio $(\mathrm{N})$ por dia. Isto permitiu que fossem aplicada as seguintes equações:

\section{Carga anual de fósforo (P):}

$\mathrm{P}=\mathrm{H}^{*} \alpha * 0,002 / 1000(6)$

$\mathrm{P}$ : quantidade de fósforo em determinado ano (ton) ano (ton)

$\mathrm{H}$ : número de habitantes no ano a

$\alpha$ : número de dias do ano $=365$

\section{Carga anual de nitrogênio (N):}

$\mathrm{N}=\mathrm{H}^{*} \alpha * 0,008 / 1000(7)$

$\mathrm{N}$ : quantidade de nitrogênio em determinado ano (ton)

$\mathrm{H}$ : número de habitantes no ano a

$\alpha$ : número de dias do ano $=365$

\subsubsection{Avaliação espaço-temporal da relação do estado trófico do reservatório de Barra Bonita (SP) com o potencial poluidor da bacia hidrográfica}


Avaliação espaço-temporal da relação entre o estado trófico do reservatório de Barra Bonita (SP) e o potencial poluidor de sua bacia hidrográfica Rachel Bardy Prado, Evlyn Márcia Leão de Moraes Novo

Tabela 1. Ponderação das classes de uso e cobertura da terra quanto à sua contribuição para o transporte de poluentes ao reservatório de Barra Bonita.

\begin{tabular}{|c|c|c|c|}
\hline $\begin{array}{l}\text { Classes de uso e } \\
\text { cobertura da terra }\end{array}$ & Características & $\begin{array}{c}\text { Nível de } \\
\text { contribuição }\end{array}$ & Peso \\
\hline $\begin{array}{l}\text { Remanescente de } \\
\text { vegetação natural }\end{array}$ & $\begin{array}{l}\text { A vegetação natural proporciona maior infiltração da água evitando erosões, } \\
\text { uma maior biodiversidade do solo e retenção de nutrientes evitando o seu } \\
\text { carreamento até os corpos d’água, além de outros benefícios ao solo e à água. }\end{array}$ & Muito baixo & P1 \\
\hline $\begin{array}{l}\text { Reflorestamento e cultura } \\
\text { permanente }\end{array}$ & $\begin{array}{l}\text { Apesar de não haver a contribuição pela diversidade das espécies, são árvores } \\
\text { de porte significativo e permanentes, trazendo alguns benefícios ao solo e à água, } \\
\text { quando cultivadas de forma adequada. }\end{array}$ & Baixo & P2 \\
\hline Cultura temporária & $\begin{array}{l}\text { Solo exposto em parte do ano, vegetação de pequeno porte que não facilita a } \\
\text { infiltração e nem segura o solo, propiciando um escoamento superficial significativo } \\
\text { e até processos erosivos, principalmente, quando o cultivo e manejo agrícola são } \\
\text { inadequados. }\end{array}$ & Médio & P3 \\
\hline Macrófita aquática & $\begin{array}{l}\text { Uma vez mortas aceleram o processo de eutrofização, contribuindo para a } \\
\text { degradação da água. }\end{array}$ & Médio & P3 \\
\hline Cana-de-açúcar & $\begin{array}{l}\text { O solo fica exposto em parte do ano favorecendo os processos erosivos e para } \\
\text { agravar a situação trata-se de uma monocultura na região de estudo, onde a } \\
\text { quantidade de agroquímicos aplicada é considerável, bem como o lançamento } \\
\text { do vinhoto gerando muitos resíduos que atingem os corpos d’água. }\end{array}$ & Alto & $\mathrm{P} 4$ \\
\hline Campo/pastagem & $\begin{array}{l}\text { São plantas monocotiledôneas como a cana-de-açúcar não oferecendo muita } \\
\text { proteção ao solo e as pastagens foram enquadradas nesta classe por ser uma } \\
\text { atividade bastante intensa em certos trechos da bacia estudada, sendo muitas } \\
\text { vezes mal manejadas, favorecendo processos erosivos, além do potencial dos } \\
\text { agroquímicos aplicados. }\end{array}$ & Alto & $\mathrm{P} 4$ \\
\hline Nuvem e sombra & Estão cobrindo, essencialmente, regiões de campo/pastagem. & Alto & P4 \\
\hline Solo exposto & $\begin{array}{l}\text { É a pior situação que se pode esperar, pois uma vez este solo exposto, iniciam-se } \\
\text { os processos erosivos que vão causar dentre outros danos ambientais o } \\
\text { assoreamento dos corpos d’água, bem como permitem um transporte livre de } \\
\text { nutrientes por meio do escoamento superficial. }\end{array}$ & Muito alto & P5 \\
\hline Área urbana & $\begin{array}{l}\text { Área geralmente impermeabilizada, facilitando o transporte de poluentes pelo } \\
\text { escoamento superficial, bem como grande fonte de poluição pontual, visto que } \\
\text { produz grande quantidade de resíduos industriais e domésticos que na sua maioria } \\
\text { são lançados in natura nos corpos d’água, acelerando o processo de eutrofização. }\end{array}$ & Muito alto & P5 \\
\hline Corpo d’água & É exatamente a classe que está recebendo o impacto. & Nenhum & 0 \\
\hline
\end{tabular}


Os valores resultantes da aplicação do IET médio foram transformados em mapas para 1990 e 2002, utilizando ferramentas do Arcview 3.2 da ESRI, sendo os níveis tróficos diferenciados com o auxílio da legenda, para cada um dos 30 pontos amostrados ao longo da bacia.

Utilizando-se o módulo Média Zonal do Spring 3.6 (INPE, 2004) foi possível espacializar os valores médios das informações contidas nas classes de uso e cobertura da terra por sub-bacia, obtendose os mapas de potencial poluidor da bacia. Posteriormente, foi realizado o cálculo de áreas para identificar a evolução das classes de 1990 para 2002.

Os mapas do estado trófico dos pontos de amostragens no reservatório de Barra Bonita, em 1990 e 2002 foram interpretados em conjunto com os mapas de potencial poluidor do uso e cobertura da terra referente também à estação chuvosa de 1990 e 2002. Foram ainda consideradas nesta análise as informações censitárias de densidade demográfica da bacia de drenagem, contabilizando a sua contribuição para o processo de eutrofização do reservatório por meio da aplicação das equações de Arceivala (1981) já descritas.

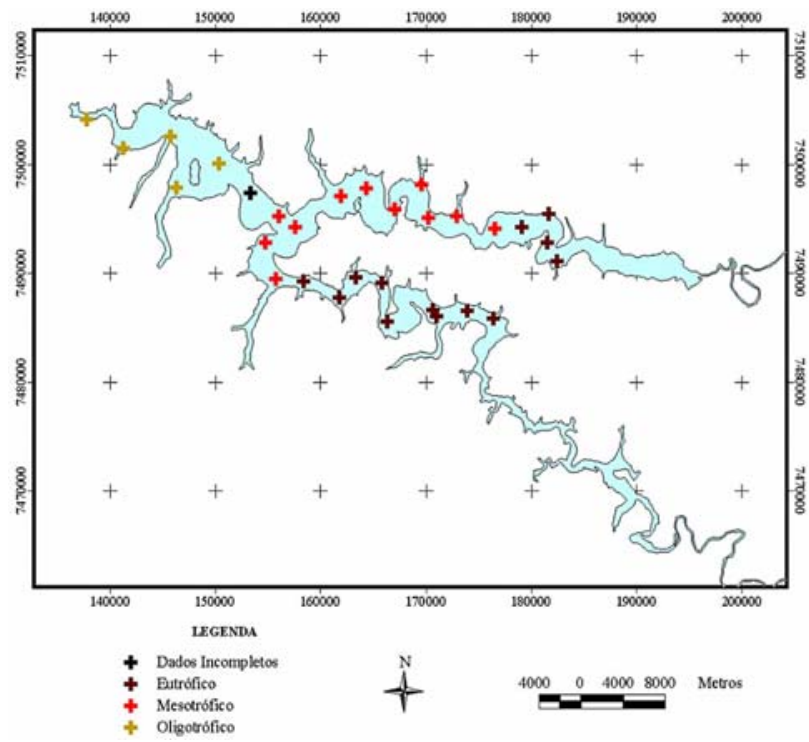

Figuras 3. Mapa do estado trófico dos pontos de amostragens no reservatório de Barra Bonita na estação chuvosa, em 1990.

\section{RESULTADOS E DISCUSSÃO}

A Tabela 2 apresenta os resultados obtidos com a aplicação do Índice de Estado Trófico (IET) de Carlson (1974), modificado por Toledo et al. (1983) e as Figuras 3 e 4 apresentam os mapas indicando a distribuição espacial do estado trófico de cada ponto de amostragem no reservatório de Barra Bonita para 1990 e 2002, no período chuvoso.

Verifica-se que em 1990, no período chuvoso, os compartimentos do reservatório de Barra Bonita apresentaram situações diferenciadas quanto ao estado trófico. Os pontos de amostragens do "braço" do rio Tietê apresentaram-se como eutróficos enquanto que os pontos do "braço" do rio Piracicaba apresentaram-se na sua maioria como mesotróficos e os pontos do "corpo" central e barragem apresentaram-se como oligotróficos. O "braço" do rio Tietê se apresentou eutrófico, em sua maioria, devido à contribuição dos esgotos domésticos (principalmente $\mathrm{N}$ e $\mathrm{P}$ ) dos grandes centros urbanos, com destaque para os resíduos da região metropolitana de São Paulo. O "braço" do rio Piracicaba apresentou-se como mesotrófico devido à contribuição também das fontes pontuais de poluição, porém, em menor escala

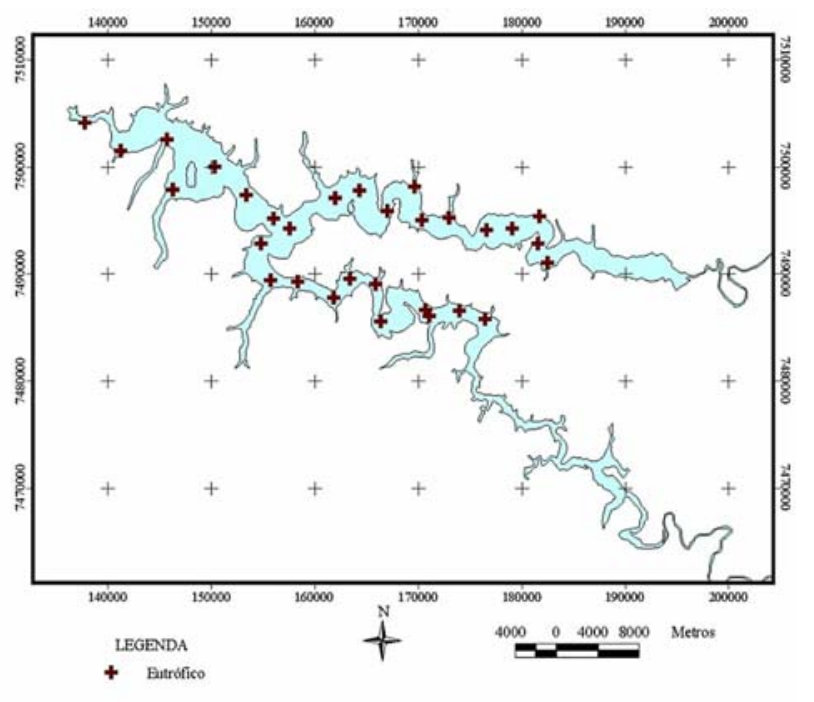

Figuras 4. Mapa do estado trófico dos pontos de amostragens no reservatório de Barra Bonita na estação chuvosa, em 2002.

Sociedade \& Natureza, Uberlândia, 19 (2): 5-18, dez. 2007 
Tabela 2. Resultado da aplicação do Índice de Estado Trófico.

\begin{tabular}{|c|c|c|c|}
\hline \multirow{2}{*}{$\begin{array}{l}\text { Compartimentos do } \\
\text { reservatório }\end{array}$} & \multicolumn{3}{|c|}{ IET Médio } \\
\hline & Pontosde coleta & 1990 Estação Chuvosa & 2002 Estação Chuvosa \\
\hline $\mathrm{P}$ & 1 & Eutrófico & Eutrófico \\
\hline$P$ & 2 & Eutrófico & Eutrófico \\
\hline $\mathrm{P}$ & 3 & Eutrófico & Eutrófico \\
\hline $\mathrm{P}$ & 4 & Eutrófico & Eutrófico \\
\hline $\mathrm{P}$ & 5 & Mesotrófico & Eutrófico \\
\hline $\mathrm{P}$ & 6 & Mesotrófico & Eutrófico \\
\hline$P$ & 7 & Mesotrófico & Eutrófico \\
\hline $\mathrm{P}$ & 8 & Mesotrófico & Eutrófico \\
\hline $\mathrm{P}$ & 9 & Mesotrófico & Eutrófico \\
\hline $\mathrm{P}$ & 10 & Mesotrófico & Eutrófico \\
\hline $\mathrm{P}$ & 11 & Mesotrófico & Eutrófico \\
\hline E & 12 & Mesotrófico & Eutrófico \\
\hline E & 13 & Mesotrófico & Eutrófico \\
\hline $\mathrm{T}$ & 14 & Eutrófico & Eutrófico \\
\hline $\mathrm{T}$ & 15 & Eutrófico & Eutrófico \\
\hline $\mathrm{T}$ & 16 & Eutrófico & Eutrófico \\
\hline $\mathrm{T}$ & 17 & Eutrófico & Eutrófico \\
\hline $\mathrm{T}$ & 18 & Eutrófico & Eutrófico \\
\hline $\mathrm{T}$ & 19 & Eutrófico & Eutrófico \\
\hline $\mathrm{T}$ & 20 & Eutrófico & Eutrófico \\
\hline $\mathrm{T}$ & 21 & Eutrófico & Eutrófico \\
\hline $\mathrm{T}$ & 22 & Eutrófico & Eutrófico \\
\hline $\mathrm{T}$ & 23 & Mesotrófico & Eutrófico \\
\hline $\mathrm{T}$ & 24 & Mesotrófico & Eutrófico \\
\hline C & 25 & Dados incompletos & Eutrófico \\
\hline C & 26 & Oligotrófico & Eutrófico \\
\hline C & 27 & Oligotrófico & Eutrófico \\
\hline C & 28 & Oligotrófico & Eutrófico \\
\hline C & 29 & Oligotrófico & Eutrófico \\
\hline B & 30 & Oligotrófico & Eutrófico \\
\hline
\end{tabular}

$\mathrm{P}=$ "braço" do rio Piracicaba (pontos de 1 a 11), T = "braço" do rio Tietê (pontos de 14 a 24), C= "corpo" central (pontos de 25 a 29), $\mathrm{E}=$ encontro dos “braços” (pontos 12 e 13) e B= barragem (ponto 30).

que no rio Tietê, mas também devido à entrada de poluentes por fontes difusas, provindos principalmente da agricultura.

O “corpo” central e barragem do reservatório apresentaram-se como oligotróficos. Isto se explica pelo maior volume de água e distância das fontes de poluição pontuais e difusas, mais uma vez comprovando a interferência dos processos de diluição e depuração na melhoria da qualidade da água. Há que se considerar também que grande parte do material que entra no reservatório é depositado antes de atingir o "corpo" central. Este, além disso, representa uma região mais profunda do reservatório, menos sujeita à ação do vento e a processos de resuspensão de nutrientes tão mais comuns nos braços do reservatório Calijuri (1988).

Por outro lado, para o ano de 2002, todos os pontos analisados apresentaram-se no estado eutrófico. Este fato indica que o processo de eutro-fização no reservatório foi intensificado de 1990 para 2002, pela entrada de nutrientes por fontes pontuais ou difusas. Na época de maiores precipitações, o tranporte de nutrientes da bacia de contribuição ao reservatório, por meio do escoamento Os resultados obtidos referentes ao crescimento populacional (Tabela 3), assim como os referentes à carga de nitrogênio e fósforo 
Avaliação espaço-temporal da relação entre o estado trófico do reservatório de Barra Bonita(SP) e o potencial poluidor de sua bacia hidrográfica Rachel Bardy Prado, Evlyn Márcia Leão de Moraes Novo

Tabela 3. Crescimento populacional de 1990 para 2002 na área de estudo.

\begin{tabular}{|l|c|c|c|}
\hline \multirow{2}{*}{ População } & Número de & Habitantes & \multirow{2}{*}{$\begin{array}{c}\text { Crescimento } \\
\text { empercentual }\end{array}$} \\
\cline { 2 - 4 } & 1990 & 2002 & 44,3 \\
\hline Urbana & 2.255 .150 & 3.254 .045 & $-2,6$ \\
\hline Rural & 206.278 & 200.847 & 40,3 \\
\hline Total & 2.461 .428 & 3.454 .892 & \\
\hline
\end{tabular}

lançada na bacia hidrográfica em estudo (Tabela 4) e o incremento no potencial poluidor difuso das subbacias estudadas em função da dinâmica do uso e cobertura da terra (Figura 5 e 6 e Tabela 5), corroboram efetivamente para este pressuposto.

Verificou-se que o crescimento populacional ocorreu na área urbana, havendo um decréscimo do número de habitantes na área rural, mostrando que houve neste período um êxodo rural, como ocorre em grande parte do país. O processo acelerado de urbanização, com a ocupação desordenada do espaço urbano também causa problemas relacionados à água, devido ao desmatamento e ocupação de encostas, nascentes e margens dos rios; lançamento de resíduos sólidos, óleos e graxas nos corpos d'água e canalização inadequada de rios. Encontram-se associados aos danos ambientais os problemas sócio-econômicoculturais como o desemprego, a marginalização, a violência, o aumento da desigualdade social, dentre outros.

Tabela 4. Carga de nitrogênio e fósforo lançados na bacia estudada.

\begin{tabular}{|l|c|c|}
\hline \multirow{2}{*}{} & \multicolumn{2}{|c|}{ Carga (toneladas) } \\
\cline { 2 - 3 } & 1990 & 2002 \\
\hline Nitrogênio & $7.187,37$ & $10.088,28$ \\
\hline Fósforo & $1.796,84$ & $2.522,07$ \\
\hline
\end{tabular}

Naturalmente, os dejetos humanos possuem uma quantidade maior de nitrogênio em relação ao fósforo, mas independente deste fato, observa-se um aumento significativo na carga de ambos os nutrientes, principalmente, nos de origem urbana que vêm sendo lançados nos corpos d'água da bacia em questão, atingindo o reservatório de Barra Bonita, com destaque para os resíduos provindos dos esgotos da Região metropolitana de São Paulo.

Comparando as Figuras 4 e 5, atenciosamente, verifica-se que ocorreram modificações de 1990 para 2002 (indicadas pelas setas em branco) na bacia estudada, mas não muito significativas em termos de área.

A Tabela 5 confirma esta constatação, visto que os valores de área das classes para 1990 e 2002 indicam que ocorreu um aumento no potencial poluidor da bacia hidrográfica, principalmente para as classes Média (5,4 km²) e Muito alta (724,6 km²).

Vários estudos têm sido realizados nas últimas décadas, no reservatório de Barra Bonita, contribuindo para a determinação do seu nível trófico. Em 1979, com a finalidade de estabelecer uma tipologia dos reservatórios do Estado de São Paulo, foi feito um estudo limnológico de 52 represas, quando foi constatado que o Reservatório de Barra Bonita era um dos mais eutrofizados da bacia do Médio Tietê, apresentando altos teores de nutrientes, alta condutividade e ocorrência de florescimentos de fitoplâncton (Matsumura-Tundisi et al., 1981).

Sociedade \& Natureza, Uberlândia, 19 (2): 5-18, dez. 2007 


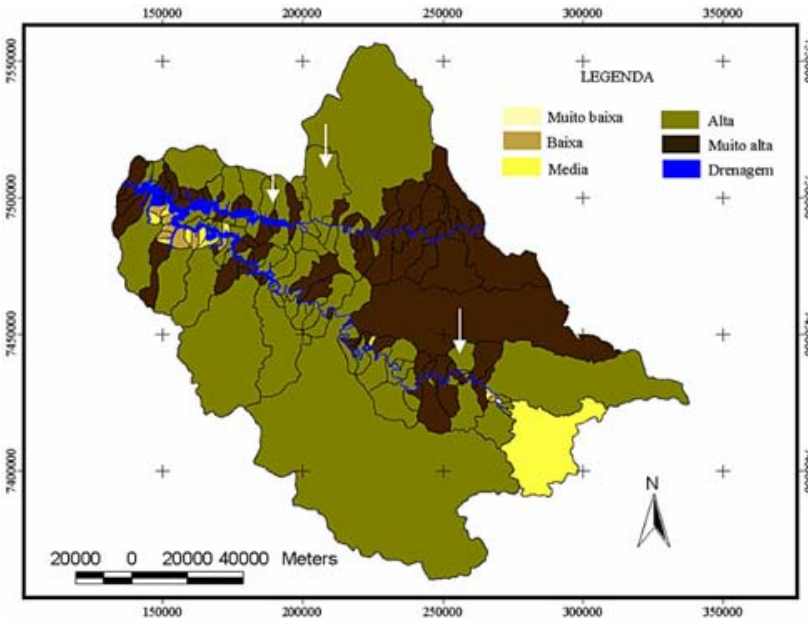

Figura 5. Mapa do potencial poluidor da bacia estudada, na estação chuvosa, no que se refere ao uso e cobertura da terra em 1990.

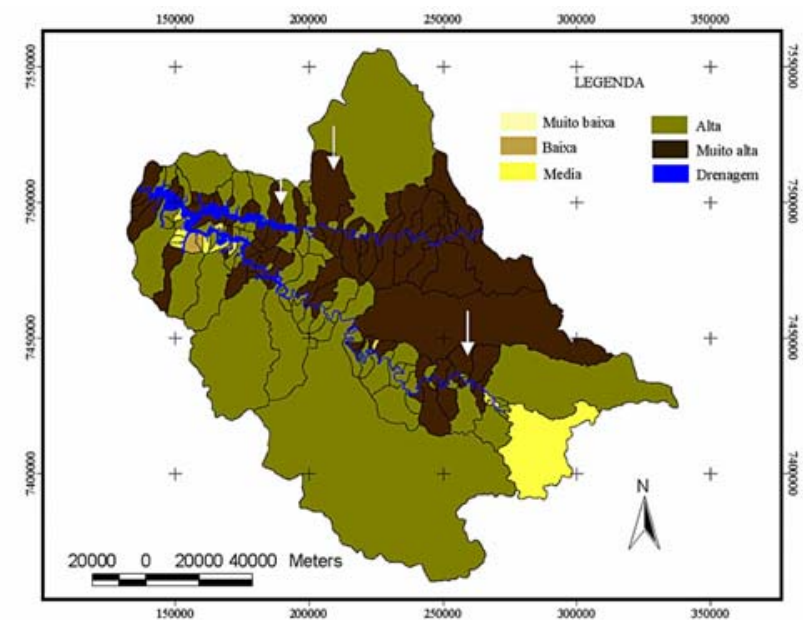

Figura 6. Mapa do potencial poluidor da bacia estudada, na estação chuvosa, no que se refere ao uso e cobertura da terra em 2002.

Tabela 5. Área das classes de potencial poluidor das sub-bacias com relação ao uso e cobertura da terra.

\begin{tabular}{|l|c|c|c|}
\hline Classes & Área $-1990(\mathrm{~km} 2)$ & Área $-2002(\mathrm{~km} 2)$ & Diferença percentual \\
\hline Muito baixa & 3,65 & 3,65 & $-70,31$ \\
Baixa & 120,58 & 50,27 & 5,4 \\
Média & 826,39 & 831,79 & $-659,69$ \\
Alta & $12.744,45$ & $12.084,76$ & 724,6 \\
Muito alta & $5.118,86$ & $5.843,46$ & \\
Drenagem & 350,5 & 350,5 & \\
\hline Total: & $19.164,43$ & $19.164,43$ & \\
\hline
\end{tabular}

Estudos realizados por Calijuri (1988) classificaram o reservatório como um sistema polimítico, controlado pela precipitação, vento, vazão e tempo de residência. De acordo com estes estudos, a coluna d'água do reservatório tende a ser permanentemente desestratificada devido à ação do vento, apresentando elevadas taxas de oxigênio dissolvido em toda sua profundidade. Quanto aos nutrientes, de modo geral, tanto o fósforo como o nitrogênio são fatores determinantes do processo de degradação da água, embora a adição de fósforo seja a principal causa do processo de eutrofização.

\section{CONCLUSÕES}

Os valores obtidos com a aplicação do IET de Carlson (1974), modificado por Toledo et al. (1983), utilizando os resultados dos parâmetros de qualidade da água de 1990 e 2002, demonstraram que o processo de eutrofização no reservatório de Barra Bonita vêm se intensificando no decorrer dos anos.

Notou-se também que houve um comportamento diferenciado nos diversos compartimentos do reservatório, sendo que o "braço" do rio Tietê foi o único compartimento cujos pontos apresentaram-se eutróficos tanto em 1990 como em 2002, mostrando que os poluentes do rio Tietê vem contribuindo há mais tempo do que os do rio Piracicaba para o proceso de degradação do reservatório de Barra Bonita. 
Os resultados obtidos referentes ao crescimento populacional de 1990 para 2002 na bacia de estudo e o aumento da carga de nitrogênio e fósforo estimado, foram importantes para justificar o possível incremento na emissão de esgotos sanitários nos cursos d'água, uma das principais fontes de poluição pontual.

Quanto às alterações no uso e cobertura da terra na bacia estudada, de 1990 a 2002, o cálculo de áreas indicou que tem ocorrido um processo gradativo de expansão das fronteiras agrícolas e urbanas, comprometendo os remanescentes de vegetação natural e gerando uma carga maior de poluentes (poluição pontual e difusa) que terão como destino os corpos d'água.

Ao se considerar o potencial poluidor da bacia de contribuição para o reservatório de Barra Bonita de 1990 para 2002, em relação ao uso do solo, percebe-se que mudanças estão ocorrendo, porém, ainda pouco perceptíveis em termos de área para a escala de estudo adotada para o mapeamento.

A intensificação do processo de eutrofização do reservatório de Barra Bonita pode comprometer os usos múltiplos a que este se destina. Portanto, torna-se necessário, que haja uma articulação da sociedade, seja por meio dos comitês de bacias ou outro meio, no sentido de adotar medidas para minimizar a carga de efluentes que é lançada na água, além de melhor ordenar a ocupação do território e adotar práticas agrícolas conservacionistas, visando reduzir as fontes difusas de poluição.

\section{AGRADECIMENTOS}

Os autores agradecem à Fundação de Amparo à Pesquisa do Estado de São Paulo (FAPESP), Processo número 00/102682-1, pelo apoio financeiro e ao Instituto de Pesquisas Espaciais (INPE) pelo apoio técnico e de infra-estrutura.

\section{REFERÊNCIAS BIBLIOGRÁFICAS}

APHA. American Public Health Association, Ame- rican Water Works Association, Water Environment Federation. Standard Methods for the Examination of Water and Wastewater.19a. Washington: Ed. Byrd. Repress Springfield, 1995. 1.134 p.

ARCEIVALA, S. J. Waste water treatment and disposal. New York: Marcel Dekker, 1981. 892 p.

BISTRICHI, C.A.; CARNEIRO, C.D.R.; DANTAS, A.S.L.; PONÇANO, W.L.; CAMPANHA, G.A.DA C.; NAGATA, N.; ALMEIDA, M.A.DE; STEIN, D.P.; MELO, M.S.DE; CREMONINI, O.A. Mapa geológico do Estado de São Paulo. São Paulo: SICCT/Pró-Minério/DCET - Instituto de Pesquisas Tecnológicas (IPT). Escala 1:500.000, 1981. v. 1 e 2, $126 \mathrm{p}$.

CALHEIROS, D. F. Ecotoxicologia de compostos organoclorados persistentes em um ecossistema eutrófico: represa de Barra Bonita (Médio Tietê SP). São Carlos, 1993. 198p. Dissertação (Mestrado) - Ciências da Engenharia Ambiental, Escola de Engenharia de São Carlos, Universidade de São Paulo.

CALIJURI, M. C. Respostas fisioecológicas da comunidade fitoplanctônica e fatores ecológicos em ecossistemas com diferentes estágios de eutrofização. São Carlos, 1988. 293p. Tese (Doutorado). Ciências da Engenharia Ambiental, Escola de Engenharia de São Carlos, Universidade de São Paulo.

CALIJURI, M. C. A comunidade fitoplanctônica em um reservatório tropical (Barra Bonita, SP). São Carlos, 1999. 211p. Tese (Livre-Docência) - Escola de Engenharia de São Carlos, Universidade de São Paulo.

CARLSON, R. E. A trophic state index for lakes. Contribution no 141. Limnological Research Center. University of Minnesota, Mineapolis, 1974. 17 p.

DALER, D.; RAUTALAHTI-MIETTINEN, E.; GRÄSLUND, S. Assessing the status of international waters. Limnology and Oceanography Bulletin, v. 10 (3), p. 37-41. 2001. 
DONZELI, P. L.; PINTO, S. A. F.; LOMBARDI NETO, F.; VALÉRIO FILHO, M.; VALERIANO, M. M. Modelo MUSLE e sistemas de informações geográficas aplicados aos estudos de pequenas bacias hidrográficas. In: X Reunião Brasileira de Manejo e Conservação do Solo e da Água, 1994, Florianópolis - SC. Anais. Campinas, 1994. 140p.

INPE. 2004. Instituto Nacional de Pesquisas Espaciais. Manuais do Sistema de Processamento de Informações Georreferenciadas (SPRING). Disponível em:<http://www.dpi.inpe.br/spring/portugues/ manuais.html> Acesso em: julho de 2004.

KIRA, T. e SAZANAMI, H. Utilização de recursos hídricos e problemas de gerenciamento de lagos. In: HASHIMOTO, M. (ed.). Diretrizes para o gerenciamento de lagos. Japão, 1995. v. 2, 6 p.

LOAGUE K.; CORWIN, D.L. e ELLSWORTH, T. R. 1998. The challenge of predicting nonpoint source pollution. Environmental Science e Technology, p. 130-133.

MATSUMURA-TUNDISI, T.; HINO, K.; CLARO, S. M. 1981. Limnological studies at 23 reservoirs in southern part of Brazil. Verh. Internat. Verein. Limnol., v. 21, p. 1.046-1.053, 1981.

MATSUMURA-TUNDISI, T.; LEITÃO, S. N.; AGUENA, L. S.; MIYAHARA, J. Eutrofização da Represa de Barra Bonita: estrutura e organização da comunidade de rotífera. Revista Brasileira de Biologia, v. 50, p. 923-935, 1990.

NOVO, E. M. L. M.; BRAGA, C. Z. F. 1991. Relatório do projeto sensoriamento remoto de sistemas aquáticos. Convênio CRHEA/USP-INPE/MCT. São José dos Campos. 75 p.

NOVO, E. M. L. M.; BRAGA, C. Z. F. 1995. Segundo relatório do projeto sensoriamento remoto de sistemas aquáticos. Convênio CRHEA/USP-INPE/ MCT. São José dos Campos. 103 p.

PEREIRA-FILHO, W. Influência dos diferentes tipos de uso da terra em bacias hidrográficas sobre sistemas aquáticos da margem esquerda do reservatório de Tucuruí - Pará. São Paulo, 2000 138p. Tese (Doutorado) - Faculdade de Filosofia, Letras e Ciências Humanas, Universidade de São Paulo.

PIÃO, A. C. S. Transporte de nitrogênio, fósforo e sedimentos pelo Ribeirão dos Carrapatos município de Itaí, SP, sua relação com usos do solo e outros impactos antropogênicos e a sua deposição no braço do Taquari (Represa de Jurumim). São Carlos, 1995. 194 p. Tese (Doutorado) - Ciências da Engenharia Ambiental, Escola de Engenharia de São Carlos, Universidade de São Paulo.

PINTO, S. A. F. 1996. Contribuição metodológica para análise de indicadores da erosão do solo utilizando técnicas de sensoriamento remoto, geoprocessamento e modelo predictivo. Rio Claro, 1996. Tese (Livre-Docência) - IGCE, UNESP.

PRADO, R. B. Geotecnologias aplicadas à análise espaço-temporal do uso e cobertura da terra e qualidade da água do reservatório de Barra Bonita, $S P$, como suporte à gestão de recursos hídricos. São Carlos, 2004. 172 p. Tese (Doutorado). Centro de Recursos Hídricos e Ecologia Aplicada, Escola de Engenharia de São Carlos, Universidade de São Paulo.

RANIERI, S. B. L. Avaliação de métodos e escalas de trabalho para determinação de risco de erosão em bacia hidrográfica utilizando sistema de informações geográficas (SIG). São Carlos, 1996.128p. Dissertação (Mestrado) - Ciências da Engenharia Ambiental, Escola de Engenharia de São Carlos, Universidade de São Paulo.

REFOSCO, J. C. Estudo comparativo da paisagem das bacias hidrográficas dos rios Araguá e da Prata. Modificações da paisagem e impactos na quantidade de material em suspensão no ambiente aquático. São Carlos, 1994. 101 p. Dissertação (Mestrado) - Ciências da Engenharia Ambiental, Escola de Engenharia de São Carlos, Universidade de São Paulo. 
THORTON, W. Perspectives on Reservoir Limnology. In THORTON, W. K. et al. (ed.) Reservoir limnology: ecological perspectives. Jonh Wiley and Sons, Inc., 1990.

TOLEDO, A.; TALARICO, M.; CHINEZ, S. J.; AGUDO, E. G. A aplicação de modelos simplificados para a avaliação do processo de eutrofização em lagos e reservatórios tropicais. IN: Congresso Brasileiro de Engenharia Sanitária e Ambiental, 12, Camboriú. Anais. 1983, p. 1-34.

TUFFORD, D. L.; Mc KELLAR JR., H.N.; HUSSEY, J.R. Stream nonpoint source nutrient prediction with land-use proximity and sasonality. Journal of Environmental Quality, 1998.

WISNIEWSKI, M. J. S. 1998. Distribuição espacial e produção secundária da comunidade zooplanctônica do reservatório de Barra Bonita - SP. São Carlos, 1998. 240p. Tese (Doutorado) - Centro de Ciências Biológicas e da Saúde, Universidade Federal de São Carlos. 